\title{
Dizer ou não dizer: a língua russa através da tradução brasileira
}

\author{
Dmitri Gurevich ${ }^{1}$
}

\begin{abstract}
The article presented here aims at discussing some characteristically marked semantic aspects of Russian language directly associated to morphological or syntactic elements. These aspects will be commented in the light of some relations between Portuguese and Russian languages and examples found in literary translations from Russian to Portuguese.
\end{abstract}

Keywords: Russian language; Portuguese language; translation.

Resumo: $\mathrm{O}$ artigo aqui apresentado tem por objetivo discutir aspectos semânticos característicos e marcantes da língua russa e que estão diretamente associados a elementos sintáticos e morfológicos. Estes aspectos semânticos serão comentados a partir de algumas relações entre a língua russa e a língua portuguesa e de exemplos presentes na prática de traduções literárias do russo para o português.

Palavras-chave: Língua Russa; Língua Portuguesa; tradução.

Um dos fenômenos mais salientes da língua russa em comparação com a portuguesa é o fato de o russo exprimir sentidos vagos e pouco definíveis do ponto de vista da semântica lexical. Não se trata aqui do léxico intraduzível do tipo "intelligêntsia", em russo, ou "saudade" ou "jeitinho brasileiro", em português. Palavras e expressões desse tipo estão bem estudados pelos filólogos e tradutores, que aprenderam a lidar com esse vocabulário, e constituem um campo lexical fechado, bastante conhecido e não muito amplo. Pelo contrário, o discurso russo opera palavras e expressões que aparecem em qualquer dicionário e, à primeira vista, não representam dificuldades. São palavras "simples", como как-mo (de um jeito), что-то (algo), какой-то (algum), такой (desse jeito; assim) e outras locuções do gênero, habitualmente classificadas pelas gramáticas tradicionais como pronomes indefinidos e pelas gramáticas modernas como determinantes. Usadas como constituintes semânticas da frase descrevendo uma realidade observável, essas palavras têm sentido fixo e podem ser traduzidas para qualquer língua. Por exemplo, “А в моих глазах точно есть что-то такое, что внушает робость" (É bem verdade que nos meus olhos há qualquer coisa que provoca timidez [Gógol]). Mas acontece muitas vezes que esses elementos da frase não têm referência direta no campo semântico, na parte proposicional da enunciação, não estão incluídos no dictum da frase. Eles aportam um matiz indefinível, fazendo parte do modus da frase. E, mais do que isso, esse modus não pode ser estruturalmente separado e sintaticamente oposto ao

\footnotetext{
${ }^{1}$ Prof. Dr. na Universidade Estatal de Moscou Lomonóssov (Rússia).
} 
dictum, o que é possível na maioria dos casos. Cf. Мне кажется, что я хочу есть (Acho que estou com fome) versus Что-то я есть хочу (Acho que estou com fome).

Esse fenômeno, que podemos chamar de "indefinição explícita", é muito característico do discurso russo. Ele compreende dois tipos de estratégia discursiva: 1) incerteza explícita, que ganha corpo nas expressões do tipo немного (um pouco), несколько (uns; poucos), какой-то (algum), как-то (de um jeito); е 2) característica densa, que se exprime nas palavras como maм (ali), mym (aqui), maк (assim), это (isso), чmo-mo (algo). Nas condições de uma comunicação natural, são essas expressões que sustentam o parâmetro pragmático da enunciação. É preciso ressaltar que as traduções portuguesas entre parênteses são corretas só no nível do dicionário. Na prática do discurso oral e escrito, as expressões russas em questão muitas vezes não têm equivalências lexicais diretas. A linguagem russa está cheia de frases como as seguintes: Что-то я сегодня устал (Estou cansado hoje, sei lá por quê), Что-то я есть / пить / спать хочу (Parece que estou com fome / com sede / com sono), Какой-то он сегодня грустный (Ele está triste hoje, não sei por quê), Я ее тут как-то видел на днях (Eu a vi um dia desses), etc. As palavras grifadas nas frases russas nem sempre podem ser traduzidas para o português e, de toda forma, a tradução não é lexicalmente direta.

Uma análise sintática superficial das frases citadas acima não ajuda, porque na frase Что-то я есть хочу (Parece que estou com fome) o pronome чmo-mo (literalmente, "alguma coisa") não é o objeto direto como ele é na frase Я хочy чmo-mo cъecmb (Quero comer "alguma coisa"). A análise sintática da frase Что-то я хочу сnать (Parece que estou com sono) dá um resultado totalmente absurdo: o pronome nunca pode ser objeto direto, já que o verbo é intransitivo. Uma análise mais profunda, que envolve a pressuposição da enunciação, permite interpretar a frase como Я хочу есть, но не понятно почему (Estou com fome, mas não sei por quê - por exemplo, faz pouco tempo que comi e é estranho estar com fome; ou a comida não foi mencionada no contexto; ou eu vi de repente a comida e senti uma fome inesperada). $\mathrm{Na}$ maioria dos casos, essas frases russas são traduzidas com explicação parecida com a que está entre colchetes. Mas a tradução do tipo "Estou com fome, mas não sei por quê" entende-se como uma frase muito artificial, se não absurda. Já em russo a frase prototípica é mais do que natural e corrente. Do mesmo modo, na frase Я ее тут както видел на днях (Eu a vi um dia desses), os advérbios mym (aqui) е как-то (de um jeito ои faz pouco), que não aparecem na tradução da frase, não marcam o tempo-espaço onde estão o falante e o interlocutor, de toda forma esse tempo-espaço não coincide com aquele em que transcorre o diálogo. Esses advérbios não marcam espaço nem tempo concretos. Sua função é indeterminar o campo espacial e temporal, por estranho que pareça. 
Surge uma questão: que valor semântico dão os falantes do russo às palavras analisadas? A meu ver, seu valor principal consiste em exprimir indefinição. Indefinição essa que não tem nada a ver com a lógica formal e é diferente do valor gramatical indeterminado que têm certos pronomes ou artigos indeterminados portugueses. Essa indefinição é mais profunda. Ela tem muita coisa em comum com uma classe de palavras chamadas partículas modais, que marcam evidentemente todo o discurso russo. A linguagem russa tende a evitar a clareza das circunstâncias. Nós, russos, deixamos o interlocutor descobrir as características (Какой-то он грустный сегодня - "Ele está algo triste hoje" Como é a tristeza dele? Por que está triste?), os pormenores (Я ее тут как-то видел на днях - "Eu a vi um dia desses" Onde? Quando? Em que circunstâncias?), as causas (Чmo-mo я есть хочy - "Estou com fome não sei por quê").

Esse fenômeno da linguagem russa é típico de vários escritores. Se pegarmos dois nomes destacados da literatura russa - Nikolai Gógol e Mikhail Bulgakov -, veremos que nas suas obras aparece muitas vezes essa indefinição. Não é raro um bom escritor usar construções típicas da linguagem falada. Até podemos dizer que o fenômeno discutido é característico desses dois escritores.

A prosa de Gógol e de Bulgakov é um exemplo interessante da mescla de narrativa literária com os princípios da linguagem dialogal. O narrador, que teoricamente deve ser o dono absoluto do campo referencial criado por ele próprio, não para de mostrar-nos a sua "segunda cara": ele brinca e faz careta como um palhaço, tentando estabelecer um contato íntimo e amigável com o leitor, um contato quase libertino. O mais importante é que o narrador se comporta como se não fosse ele quem tivesse ideado os acontecimentos e personagens do texto, mas simplesmente comenta as coisas que o leitor até que pode ter ouvido antes. Esse fenômeno é amplamente conhecido como polifonia narrativa, primeiramente descrita por Mikhail Bakhtine e mais tarde elaborado por E. Benveniste, Lyons e dezenas, se não centenas, de filólogos. A ideia desse fenômeno consiste em que o espaço virtual da narrativa, que é autossuficiente por natureza e tem a anáfora como ponto de referência, cruza-se com o espaço "real" do diálogo possível entre o narrador e o leitor, o espaço que tem o dêixis como seu ponto de referência e o conhecimento comum de coisas tratadas. O exemplo da narrativa clássica na literatura russa é Tolstói; na literatura brasileira é Alencar. O exemplo da narrativa polifônica é Gógol, Bulgakov, Dostoiévski; no Brasil são textos de Machado de Assis, Mário de Andrade, entre outros.

A entonação de Gógol e de Bulgakov parece subjetivamente viva porque se baseia nos princípios típicos da linguagem falada. Os textos estão cheios de partículas modais que 
dirigem o leitor à pressuposição do enunciado, fato que cria uma ilusão do conhecimento de coisas comum ao leitor e ao narrador; elementos linguísticos que dão avaliação subjetiva ao tema do discurso: sufixos avaliativos (morfemas diminutivos e aumentativos), expressões coloquiais, sintaxe coloquial: a inversão de tópico e foco, o que não é típico da narrativa; e outras coisas.

Essas particularidades da linguagem russa muitas vezes aparecem nos textos de Gógol e Bulgakov. O tradutor brasileiro tem que superar sistematicamente a resistência da sua própria língua, para a qual essa subjetividade ou indefinição é marcada estilisticamente ou simplesmente impossível. Vamos comparar alguns exemplos de O Capote e O Inspetor Geral, de Gógol, e de Margarita e o Mestre, de Bulgakov, em russo e em português. Cabe dizer que as traduções para o português são muito boas, foram feitas por especialistas em língua e literatura russa de nível profissional altíssimo e refletem todas as nuances do texto. Mas, mesmo assim, ao analisar paralelamente dois textos podemos ver diferenças sistemáticas que não se devem à estrutura do texto, e sim à estrutura da própria língua.

Há contextos em que a indefinição semântica no texto original tem como equivalência na tradução uma das acepções possíveis, mas não a única:

1. Какие всё имена; я, право, никогда и не сльхивала таких. (O Capote)

1a. Esses nomes, só sendo castigo; nunca ouvi nomes tão esquisitos.

2. Вряд ли где можно было найти человека, который так жил бы в своей должности. (O Capote)

2a. Seria difícil encontrar uma pessoa tão consumida no seu posto.

3. Некоторые буквы у него были фавориты, до которых, если он добирался, то был сам не свой... (O Capote)

3a. Tinha algumas letras favoritas e, se chegava a escrevê-las, sentia-se enlevado...

4. Акакий Акакиевич уже заблаговременно почувствовал надлежащую робость, несколько смутился. (O Capote)

4a. A. A. já sentira de antemão a necessária timidez; meio confuso.

5. Да так, уж он умер, четвертого дня похоронили. (O Capote)

5a. Muito simples, ele morreu, foi enterrado há quatro dias. 
6. Мне всегда как-то лучше работается за городом, в особенности весной. (Margarita e o Mestre)

6a. Eu acho que trabalho sempre melhor fora da cidade, em especial na primavera.

Nos exemplos 1 a 6 , o elemento grifado na tradução tem um sentido mais preciso e concreto do que o seu protótipo russo. No entanto, não dá para dizer que o sentido na tradução seja errado. O equivalente português, sendo mais definido, carece um pouco de extensão e resulta menos amplo. Claro que isso não é "culpa" do tradutor, nada disso! É, por assim dizer, "culpa" da língua, que não admite tal tipo e tal grau de indefinição.

Não é raro omitir um elemento de indefinição do texto original na tradução. Esse elemento costuma anteceder outra palavra ou sintagma, perfeitamente traduzido, que tem um significado mais concreto. Nos exemplos a seguir (7 a 14), os elementos omitidos estão marcados com o signo $\emptyset$.

7. Сегодня мне всю ночь снились какие-то две необыкновенные крысы. Право, этаких я никогда не видывал. (O Inspetor Geral)

7a. Sonhei esta noite toda com $\emptyset$ duas ratazanas impressionantes. Palavra de honra, nunca vi nada parecido.

8. Уже по самому имени видно, что она когда-то произошла от башмака. (O Capote)

8a. O nome derivado $\emptyset$, como se vê, de bachmak - botina.

9. Там, в этом переписывании, ему виделся какой-то свой разнообразный и приятный мир. (O Capote)

9a. Ø Naquele infindável transcrever, vislumbrava algo como um mundo mais diverso e agradável.

10. Итак, во избежание всяких неприятностей, лучше департамент, о котором идет дело, мы назовем одним департаментом. (O Cароте)

10a. Portanto, para evitar $\emptyset$ complicações, é melhor denominarmos o departamento de que falamos... de um certo departamento. 
11. Да, обстоятельство такое... необыкновенно, просто необыкновенно. (O Inspetor Geral)

11a. É verdade. Que $\varnothing$ situação extraordinária, muito extraordinária.

12. Да я только так заметил вам. (O Inspetor Geral)

12a. Bem, eu só queria $\emptyset$ lembrar você.

13. - Разрешите мне присесть? - вежливо попросил иностранец, и приятели как-то невольно раздвинулись. (Margarita e o Mestre)

13a. - Permitem que me sente? - pediu com polidez o estrangeiro, e, $\varnothing$ involuntariamente, os amigos afastaram-se.

14. Безглавое тело как-то нелепо загребло ногами и село на пол. (Margarita е о Mestre)

14a. O corpo decapitado deu $\varnothing$ absurdamente alguns passos e sentou-se no chão.

A substituição de um elemento indefinido por outro mais definido ou a omissão de um elemento são comuns nas traduções portuguesas de textos russos, embora, no nível paradigmático, a língua portuguesa disponha de meios lexicais e gramaticais para exprimir sentidos "dêiticos vagos" como, por exemplo, "assim", "desse jeito", "de um jeito qualquer", "algo", "algum", "um", etc. A omissão sistemática não mostra o fato de o português não ser capaz de exprimir esses sentidos, mas que o português (e muitas outras línguas ocidentais, como o francês e o espanhol, entre outras) resiste ao uso não típico, não determinado dessas locuções e os falantes de português evitam certo abuso da língua, tentando não usar esses elementos que lhes parecem conturbar e abrumar o sentido da frase, embaraçando a compreensão do texto em geral.

\section{Referências bibliográficas}

Бахтин, М.М. Проблемы поэтики Достоевского. Москва: Художественная литература. 1972.

Bulgakov, Mikhail. Margarita e o Mestre. Lisboa: Colecção Mil Folhas, 2002. Tradução: António Pescada. 
Gógol, Nikolai. O Capote e Outras Histórias. Rio de Janeiro: Civilização Brasileira, 1990. Tradução: Paulo Bezerra.

. Teatro Completo. São Paulo: Editora 34, 2009. Tradução: Arlete Cavaliere. 